\title{
0 atendimento educacional especializado e a utilização das tecnologias digitais nas salas de recursos multifuncionais
}

Jackson Ronie Sá-Silva ${ }^{1}$ Ana Paula Almeida Ferreira ${ }^{2}$ Jarlisse Nina Beserra da Silva ${ }^{3}$ Maritania dos Santos Padilha ${ }^{4}$

\begin{abstract}
Resumo:
A discussão neste artigo tem como objetivo compreender o que as pesquisas no campo da educação inclusiva revelam sobre o uso das tecnologias digitais no atendimento educacional especializado (AEE) em salas de recursos multifuncionais (SRM), referente ao período de 2016 a 2020. Na realização de levantamento bibliográfico, foram identificados onze artigos que versavam sobre a temática, adquiridos no portal de Periódicos da CAPES, Google Acadêmico e Scielo. Os resultados revelam que as tecnologias digitais podem potencializar aprendizagens dos alunos público-alvo da educação especial (PAEE) e fortalecer o processo de inclusão em todos os âmbitos. São reconhecidas algumas problemáticas no AEE que necessitam ser superadas, tais como: espaços reduzidos e pouco acessíveis para o desenvolvimento das atividades pedagógicas; carência de qualificação docente e falta de articulação entre o professor do AEE e o professor da sala regular; ausência ou restrição de Internet e escassez de projetos e estudos voltados ao PAEE. Aponta-se para a necessidade de políticas públicas que assegurem a implementação das tecnologias digitais no processo educativo de estudantes PAEE, visando à acessibilidade e ao desenvolvimento dos estudantes.
\end{abstract}

\footnotetext{
1 Professor Adjunto do Departamento de Biologia da Universidade Estadual do Maranhão (DBIO - UEMA) e Líder do Grupo de Pesquisa Ensino de Ciências, Saúde e Sexualidade (GP-ENCEX/UEMA). Doutor em Educação pela UNISINOS. Pós-Doutor em Educação pela UFRGS. Professor do Programa de Pós-Graduação em Educação da Universidade Estadual do Maranhão (PPGE - Mestrado Profissional/UEMA). Professor do Mestrado Profissional em Educação Inclusiva em Rede (PROFEI) da Universidade Estadual do Maranhão (UEMA). E-mail: prof.jacksonronie.uema@gmail.com. ORCID iD: https://orcid.org/0000-0001-9607-3674. 2 Discente do Programa de Mestrado Profissional em Educação Inclusiva em Rede (PROFEI) da Universidade Estadual do Maranhão (UEMA). Especialista em Educação Inclusiva pela Universidade Cidade de São Paulo (UNICID). Especialista em Psicologia da Educação pela Universidade Estadual do Maranhão (UEMA). Especialista em Docência na Educação Infantil pela Universidade Federal do Maranhão (UFMA). Licenciada em Pedagogia pela Universidade Federal do Maranhão (UFMA). Professora da Rede Municipal de Educação de São Luís - MA (SEMED). E-mail: paula_almeida28@hotmail.com. ORCID iD: https://orcid.org/0000-0002-9515-7494.

3 Discente do Programa de Mestrado Profissional em Educação Inclusiva em rede (PROFEI) pela Universidade Estadual do Maranhão (UEMA). Especialista em Arte Mídia e Educação pelo Instituto Federal de Educação, Ciência e Tecnologia do Maranhão (IFMA). Bacharela em Serviço Social pela Universidade Federal do Maranhão (UFMA). Licenciada em Pedagogia pela Universidade Estadual do Maranhão (UEMA). Professora da Rede Municipal de Educação de São Luís - MA (SEMED). E-mail: jarlisse@hotmail.com. ORCID iD: https://orcid.org/0000-0001-8629-5855.

4 Discente do Programa de Mestrado Profissional em Educação Inclusiva em Rede (PROFEI) da Universidade Estadual do Maranhão (UEMA). Especialista em Língua Brasileira de Sinais pela Faculdade Mantenense dos Vales Gerais (INTERVALE). Licenciada em Letras pela Universidade Metropolitana de Santos (UNIMES). Professora da Rede Estadual de Educação do Maranhão (SEDUC). E-mail: maritaniasantos30@gmail.com. ORCID iD: https://orcid.org/0000-0003-2472-4428.
} 


\title{
Palavras-chave:
}

Inclusão escolar. Atendimento Educacional Especializado. Tecnologias digitais de informação e comunicação.

\section{Special educational services and the use of digital technologies in multifunctional resource rooms}

\begin{abstract}
:
The discussion in this article aims to understand what the researches in the field of inclusive education reveals about the use of digital technologies in specialized educational care (SEC) in multifunctional resource classrooms (MRC), referring to the period 2016 to 2020. In the bibliographic survey, 11 articles were identified that related to the theme, acquired in the portal of CAPES Journals, Google Scholar and Scielo. The results reveal that digital technologies can enhance learning from the target public students of special education (TPSE) and strengthen the inclusion process in all areas. Some problems in the SEC that need to be overcome are recognized, such as: reduced and inaccessible spaces for the development of pedagogical activities; lack of teacher qualification and lack of articulation between the SEC teacher and the regular classroom teacher; absence or restriction of the Internet and scarcity of projects and studies aimed at the TPSE. It points to the need for public policies that ensure the implementation of digital technologies in the educational process of TPSE students, aiming at the accessibility and development of students.
\end{abstract}

Keywords:

School inclusion. Specialized Educational Service. Digital information and communication technologies.

\section{Atendimiento educacional especializado y la utilización de las tecno- logias digitales en aulas de recursos multifuncionales}

\section{Resumen:}

La discusión en este artículo tiene como objetivo comprender lo que las investigaciones, en el campo de la educación inclusiva, revelan sobre el uso de las tecnologías digitales en la Atención Educativa Especializada (AEE) en salones de clase inclusivos, referentes al periodo del 2016 al 2020 . En el relevamiento bibliográfico se identificaron 11 artículos que abordaban el tema, estos fueron adquiridos en el portal de Periódicos CAPES, Google Académico y Scielo. Los resultados revelan que las tecnologías digitales pueden aumentar los aprendizajes de los alumnos (público objetivo) de la educación inclusiva (TPSE), además de fortalecer el proceso de inclusión en todos los ámbitos. También fueron reconocidas algunas problemáticas de la AEE, las cuales necesitan ser mejoradas, tales como: espacios reducidos y poco accesibles para el desarrollo de actividades pedagógicas; déficit de calificación docente, así como falta de articulación entre docentes de AEE y los docentes de aula general; ausencia o restricción de internet y escasez de proyectos o estudios dirigidos al TPSE. Se señala la necesidad de políticas públicas que aseguren la implementación de tecnologías digitales en el proceso de educación de los estudiantes TPSE, buscando así la accesibilidad y el desarrollo de los estudiantes.

\section{Palabras clave:}

Inclusión escolar. Atención Educacional Especializado. Tecnologias digitales de información y comunicación. 


\section{Introdução}

A partir do início do século XXI, a sociedade brasileira vem sendo cenário de profundas mudanças no campo da educação especial, tendo como marco inicial o Programa Educação Inclusiva: direito à diversidade. Entretanto, foi a partir da criação da Política de Educação Especial na Perspectiva da Educação Inclusiva de 2008 que houve o fortalecimento da inclusão de alunos público-alvo da educação especial (PAEE) nas escolas. A partir de então, outros dispositivos legais foram criados para garantir o acesso, a permanência e aprendizagem desse alunado nas instituições de ensino baseadas no princípio de educação inclusiva.

Dessa maneira, compreendemos que a inclusão de alunos PAEE no ensino comum, pautada no princípio da diversidade, se compromete com a formação integral, levando em consideração as especificidades e as potencialidades apresentadas por cada um, isto é, a educação a eles oferecida deve ter os mesmos significados e sentidos que ela tem para os alunos que não apresentam deficiências. Nesse contexto, é importante compreender que a escola inclusiva "[...] atende a todos e [...] reconhece as singularidades de cada um, afinal, todos nós, pessoas com ou sem deficiência, somos seres únicos, com potencialidades e necessidades. Ela rompe com os preconceitos e enxerga a diversidade como valor" (SOMOS EDUCAÇÃO, 2020, p. 4).

Os dispositivos legais que tratam sobre a educação especial apontam algumas providências para a inclusão dos alunos PAEE, como atendimento educacional especializado (AEE), que corresponde a um importante serviço que contempla equipamentos, recursos humanos e materiais para a garantia do acesso e da participação plena no processo de inclusão. Dentre os equipamentos e recursos utilizados no AEE, enfatizamos, neste estudo, o uso das tecnologias digitais como importante aliado no processo de ensino-aprendizagem. Como esclarecem Straub et al.:

As tecnologias digitais estão presentes em vários contextos de nossa sociedade e permeiam nossas relações sociais, econômicas e de trabalho. Diante desse contexto, a educação não pode se furtar de usufruir das tecnologias nos processos de ensino e aprendizagem (STRAUB et al., 2020, p. 103).

Considerando a relevância que as tecnologias digitais exercem no campo educacional, o interesse por este estudo emergiu da necessidade de compreender como as tecnologias vêm contribuindo com a inclusão escolar dos alunos PAEE, especificamente nos espaços onde funciona o AEE. Essa inquietação surgiu no decorrer dos estudos realizados no Mestrado Profissional em Educação Inclusiva - PROFEI/UEMA -, na disciplina Inovação e Tecnologias Digitais de Informação e Comunicação na Educação, em que refletimos e discutimos o contexto tecnológico digital contemporâneo e suas relações com os processos de ensino e aprendizagem.

Por entendermos o quanto a utilização das tecnologias digitais no AEE contribui significativamente no processo de inclusão escolar dos alunos PAEE, este estudo partiu e propôs responder ao seguinte questionamento: o que nos mostram as pesquisas científicas acerca da utilização das tecnologias digitais como recursos pedagógicos no atendimento educacional especializado realizado nas salas de recursos multifuncionais no período de 2016 a 2020 ?

A partir dessa reflexão, o presente estudo teve como objetivos: compreender o que as pesquisas científicas revelam acerca do uso das tecnologias digitais no atendimento educacional especializado nas salas de recursos multifuncionais, referente ao período de 2016 a 2020; descrever a concepção, estrutura e o funcionamento do AEE de acordo com os documentos legais e estudiosos da área; verificar a relevância das tecnologias digitais para a educação especial; e identificar os principais aspectos evidenciados pelas pesquisas sobre as práticas pedagógicas com o auxílio das tecnologias no AEE. 
O artigo está estruturado em cinco seções. Na primeira, abordamos as definições, características, a função, o funcionamento e o profissional do AEE. Na segunda, enfatizamos as tecnologias digitais na educação especial. Em seguida, descrevemos o percurso metodológico utilizado para a realização da pesquisa. Na quarta seção, realizou-se a apresentação, discussão e análise dos resultados das pesquisas. E, por fim, foram apresentadas as considerações finais sobre o entendimento dos resultados decorrentes deste estudo.

Diante do exposto, pretende-se com este estudo ampliar nossos conhecimentos acerca da temática, colaborando com estudiosos interessados no assunto e, principalmente, que possa contribuir de forma significativa com os professores e os alunos do AEE no que tange à utilização das tecnologias digitais no processo de construção de conhecimentos.

\section{Atendimento educacional especializado}

O AEE é um dos serviços ofertados pela educação especial na perspectiva da educação inclusiva. Esse atendimento é diferenciado da sala regular, uma vez que utiliza recursos, serviços e atividades pedagógicas diversificadas com o intuito de desenvolver as habilidades necessárias para que os alunos PAEE tenham acesso às aprendizagens da sala comum.

Nesse contexto, apresentamos alguns documentos legais que sancionam a educação como um direito de todos e, especificamente, acerca do AEE. A Constituição Federal de 1988 garante o direito à escolarização a todos, assegurando em seu Art. 205 que:

A educação, direito de todos e dever do Estado e da família, será promovida e incentivada com a colaboração da sociedade, visando ao pleno desenvolvimento da pessoa, seu preparo para o exercício da cidadania (BRASIL, 1988, Art. 205).

A mesma Lei também deixa clara a garantia do AEE aos alunos com deficiência, quando considera, em seu Art. 208, inciso III, "[...] atendimento educacional especializado aos portadores de deficiência preferencialmente na rede regular de ensino" (Ibidem).

Nessa compreensão de educação para todos, a Política Nacional de Educação Especial, na Perspectiva da Educação Inclusiva (BRASIL, 2008), define a educação especial como uma modalidade de ensino transversal a todos os níveis, as etapas e modalidades, com a oferta do AEE, que, segundo Alves et al. (2006, p. 15), corresponde a:

[...] parte diversificada do currículo dos alunos com necessidades educacionais especiais, organizado institucionalmente para apoiar, complementar e suplementar os serviços educacionais comuns. Dentre as atividades curriculares específicas desenvolvidas no atendimento educacional especializado em salas de recursos se destacam: o ensino da Libras, o sistema Braille e o Soroban, a comunicação alternativa, o enriquecimento curricular, dentre outros.

O ambiente da sala de AEE é diferenciado de uma sala regular, pois não se detém a ensinar conteúdos curriculares aos alunos. Trata-se de um serviço que identifica, elabora e organiza recursos pedagógicos e de acessibilidade que eliminem as barreiras para a plena participação dos alunos, considerando suas necessidades específicas (Ibidem). Dessa forma, o AEE tem a função de:

[...] complementar ou suplementar a formação do aluno por meio da disponibilização de serviços, recursos de acessibilidade e estratégias que eliminem as barreiras para a plena participação na sociedade e desenvolvimento de sua aprendizagem (Resolução CEB/CNE nº 4, 2009, Art. 2). 
A Resolução no 4 de 2009, um dos dispositivos que conferem operacionalidade à Política de 2008, estabelece as diretrizes para o AEE e define o grupo específico da educação especial. São eles: pessoas com deficiência (física, intelectual, mental ou sensorial), transtornos globais do desenvolvimento e altas habilidades/superdotação (Ibidem).

O Decreto $n^{\circ} 7.611$ de 2011, que dispõe sobre a educação especial, o atendimento educacional especializado e dá outras providências, estabelece os seguintes objetivos no que se refere ao AEE:

I - prover condições de acesso, participação e aprendizagem no ensino regular e garantir serviços de apoio especializado de acordo com as necessidades individuais dos estudantes;

II - garantir a transversalidade das ações da educação especial no ensino regular;

III - fomentar o desenvolvimento de recursos didáticos e pedagógicos que eliminem as barreiras no processo de ensino e aprendizagem; e

IV - assegurar condições para a continuidade de estudos nos demais níveis, etapas e modalidades de ensino (BRASIL, 2011, $\S 1^{\circ}$, Art. $1^{\circ}$ ).

O AEE, para os alunos PAEE, deve ser ofertado, preferencialmente, nas salas de recursos multifuncionais (SRM). Nessas salas, devem ser desenvolvidas estratégias pedagógicas de ensino-aprendizagem que favoreçam o acesso dos estudantes aos conteúdos curriculares, bem como a participação no ambiente escolar. Para isso, esse espaço deve ser organizado com materiais didático-pedagógicos, equipamentos e profissionais especializados (ALVES et al., 2006).

A Nota Técnica no 11 de 2010 (BRASIL, 2010) aponta alguns critérios necessários para a implantação da SRM, como: contemplação no Projeto Político-Pedagógico (PPP) da escola a oferta de AEE; professor especializado em educação especial; materiais garantidos pelos documentos legais; e acessibilidade aos educandos. É função da escola elaborar o PPP tendo em vista a flexibilidade da organização do AEE, conforme o Plano de AEE de cada aluno; matricular nas salas de recursos os alunos público-alvo da educação especial que se encontram matriculados no ensino regular na própria escola ou em outra escola, de acordo com a demanda da rede de ensino; fazer o registro no Censo Escolar Ministério da Educação (MEC)/Instituto Nacional de Estudos e Pesquisas Educacionais Anísio Teixeira (INEP) dos alunos da educação especial matriculados, tanto na classe comum quanto na SRM da escola; promover articulação entre professor da SRM com professor da sala regular; estabelecer redes de apoio e colaboração com as demais escolas da rede; e, por fim, promover a participação dos alunos nas ações intersetoriais articuladas aos serviços públicos de saúde, assistência social, entre outros.

Com relação ao profissional que atua na SRM, é necessário que este tenha formação inicial que o habilite para a função docente e formação na área da educação especial. As atribuições do professor da SRM correspondem a: identificar, elaborar, produzir e organizar serviços, recursos pedagógicos de acessibilidade e procedimentos de acordo com as necessidades específicas dos educandos da educação especial; elaborar e desenvolver o plano de AEE, que é individual; determinar se o atendimento será individual ou coletivo e o número de frequência semanal de cada aluno; e ensinar e usar a tecnologia assistiva $(\mathrm{TA})^{5}$ para a ampliação de habilidades, promovendo a autonomia e participação do educando (BRASIL, 2009).

Cabe ao professor da SRM, além das atribuições citadas, auxiliar na funcionalidade, execução de recursos pedagógicos e acessibilidade na sala regular ou em outros locais da escola; orientar as famílias e os professores da classe comum; e propor articulação com os professores da sala comum. Para isso, ressalta-se a importância de buscar parcerias com áreas afins (Ibidem).

5 É "[...] todo o arsenal de recursos e serviços que contribuem para proporcionar ou ampliar habilidades funcionais de pessoas com deficiência e, consequentemente, promover vida independente e inclusão" (BERSCH, 2007, p. 31). 
É importante ressaltar, no que concerne ao papel do professor especializado no AEE, como enfatiza Baptista (2020), sua indispensável atuação no processo da inclusão escolar, uma vez que possibilita caminhos de aprendizagens satisfatórios e desafiadores para os alunos PAEE. Nesse contexto, a sala de recursos como apoio pedagógico se torna elemento prioritário nos dispositivos legais, como já citamos.

Diante do exposto, é importante reconhecer o AEE como um ambiente flexível que tem como meta sanar as necessidades de cada educando da educação especial e proporcionar acessibilidade ao currículo escolar. O AEE constitui um conjunto de procedimentos específicos para a aprendizagem e desenvolvimento de diversas habilidades, não podendo ser confundido como um espaço de reforço escolar para aprofundar os conteúdos escolares.

\section{Tecnologias digitais na educação especial}

Atualmente, vivemos em uma sociedade em que todos os âmbitos são mediados por algum recurso tecnológico. Estamos inseridos em um contexto no qual não podemos nos evadir da influência e do alcance da tecnologia, seja nas nossas experiências profissionais ou pessoais.

Considerando que a cultura digital ${ }^{6}$ está presente no cotidiano da sociedade contemporânea, estabelecendo novas formas de ver e estar no mundo, o papel da informação e do conhecimento nesse contexto coloca a escola como instituição formadora de um novo perfil de homem que atenda às novas formas de pensar e interagir em face às demandas de um mercado cada vez mais competitivo (TERUYA, 2006). Nesse sentido, a educação é lançada a esse fenômeno, sob as novas perspectivas diante dos processos de ensinar e aprender.

A era digital em que vivemos não permite mais que a escola permaneça alheia à tecnologia, visto que os sujeitos que formam o corpo escolar utilizam recursos tecnológicos fora da escola, inclusive os próprios alunos.

As cidades contemporâneas já estão sob o signo do digital e basta olharmos à nossa volta para constatarmos celulares, palms, televisão por cabo e satélite, internet de banda larga e wireless, cartões inteligentes, etc. Vivemos já na cibercidade, trazendo novas questões na intersecção entre o lugar e o fluxo. Aqui surgem questões como a cibercidadania, a ciberdemocracia, a exclusão e inclusão digital (LEMOS, 2003, p. 8).

Uma vez que os sujeitos que compõem o espaço escolar fazem uso das mais variadas mídias na vida social, é essencial que também possam ter contato com as mídias dentro do ambiente escolar. Estamos diante de um novo modelo de estudante, logo, precisamos ter um novo modelo de escola, um novo modelo de professor. O educador precisará ver "[...] as novas ferramentas tecnológicas como um aliado na árdua tarefa de motivar, cativar e despertar para o caminho do conhecimento" (RICOY; COUTO, 2009, p. 147 Apud COUTINHO, 2011, p. 12).

Embora já possa ser notado um tímido avanço diante das recentes abordagens no que se refere ao uso da tecnologia nos ambientes escolares, ainda há uma certa limitação por parte de muitos profissionais da educação em utilizar recursos tecnológicos no processo educativo. De acordo com Silva, a razão maior para este quadro é o "[...] fato de que a tipologia de ensino dominante na escola é a centrada no professor" (SANCHO, 2006, p. 19 Apud SILVA, 2017, p. 325). Ainda perdura a ideia de um docente detentor de todo o conhecimento, que o transmite aos alunos de forma unilateral e

6 Segundo Lemos, a cultura digital, também chamada de cibercultura, "[...] é a cultura contemporânea marcada pelas tecnologias digitais" (2003, p. 1) 
pouco colaborativa. Aqui, poucos são os recursos tecnológicos utilizados e, quando o são, servem como suporte para práticas antigas.

Dessa forma, faz-se necessário que o professor desenvolva o que Masetto vai chamar de "mediação pedagógica", na qual o docente assumirá "[...] o papel de orientador das atividades do aluno, de consultor, de facilitador da aprendizagem, desempenhará o papel de quem trabalha em equipe, junto com o aluno, buscando os mesmos objetivos." (MASETTO, 2006, p. 142).

Uma mediação pedagógica de qualidade, diante do uso das tecnologias na educação, é um fator imprescindível no processo de ensino-aprendizagem, pois o professor deverá estar dotado de conhecimentos científicos e tecnológicos a fim de oportunizar aos estudantes novas possibilidades para a construção saberes, como:

A utilizar outras linguagens (sonora, visual, audiovisual) que motivam a compreensão dos alunos em sua diversidade de estilos de aprendizagem. Para os alunos com deficiências, por terem limitação em uma determinada linguagem, essas tecnologias podem abrir a possibilidade de compreensão, como por exemplo, apresentação em PowerPoint com texto e imagem, com um artefato que permite que o aluno cego possa ter a descrição dos elementos visuais presentes na apresentação (CORTELAZZO, 2012, p. 116).

As tecnologias digitais apresentam-se, nesse sentido, como potenciais aliadas da ampliação de oportunidades educativas, visto que a instalação dos laboratórios ou das salas de recursos multifuncionais bem equipadas de nada servirão se não houver quem as manuseie de forma adequada (SILVA, 2017).

No entanto, é importante observar que há uma diversidade de práticas educativas que perpassam o contexto de muitos profissionais e alunos quanto ao uso de tecnologias na escola. Ao pesquisarem sobre a caracterização física de salas de recursos multifuncionais e percepções de professores em relação à presença de jogos e tecnologia no atendimento educacional especializado, Spurio e Bianchini (2020, p. 2012), observaram que:

De um lado, pode-se ter salas que apresentam materiais variados, incluindo jogos digitais, e um professor com dificuldades para sua utilização. Mas também é possível encontrar um espaço empobrecido de tecnologias e um professor criativo. Tanto a criatividade do professor quanto a presença de materiais e tecnologias são importantes de modo a promover a aprendizagem do aluno.

Dessa forma, quer seja nas atividades nas salas comuns, quer seja nas salas especiais, a mediação do professor poderá ser um diferencial na busca pela aprendizagem do discente. Uma vez que a tecnologia já faz parte da vida em sociedade, podemos dizer que estamos trilhando um caminho sem volta, onde não mais é possível nos isentarmos das influências tecnológicas que nos cercam. Cabe a nós profissionais da educação utilizarmos a tecnologia a nosso favor, contribuindo para um ensino-aprendizagem eficaz e colaborativo.

Essa necessidade de fazermos uso das colaborações que os recursos digitais têm a nos oferecer é visível tanto nas salas de aula comuns como nas salas especiais, onde são atendidos alunos com deficiência. As tecnologias digitais têm potencial para criar novas formas de atuar no contexto da educação especial/inclusiva e contribuir para o reconhecimento das diferenças à medida que apresenta uma variedade de recursos, que ampliam e podem favorecer as aprendizagens diante de diferentes especificidades e peculiaridades de estudantes PAEE. Segundo Jannuzzi, (1998, p. 29-30), "[...] a utilização dos recursos da informática na área da Educação Especial representa um importante papel no sentido de facilitar a produção dos conhecimentos culturalmente construídos e que se encontram fora do alcance dessas pessoas". 
Dessa forma, quando utilizada com a intencionalidade pedagógica, as tecnologias digitais podem tanto se constituir como recurso didático facilitador de aprendizagens como também um instrumento diferenciado de avaliação que considere as especificidades de cada um, atuando como um instrumento de novas possibilidades educativas.

Essa intencionalidade pedagógica parte da premissa de que as tecnologias digitais, por si só, não podem garantir a aprendizagem do aluno. O professor, como mediador, precisa conhecê-las, compreendê-las e saber utilizá-las de forma a promover ações pedagógicas que, de fato, sejam inclusivas.

Essa mediação do professor no âmbito do AEE pressupõe como foco não as limitações, mas as potencialidades dos alunos frente à escolha de ferramentas que contribuam para o atendimento de suas necessidades e favoreçam suas aprendizagens. Para tanto, o profissional deve contar com conhecimentos tanto no âmbito do manuseio das ferramentas digitais quanto na sua escolha a partir as propostas educativas, pois:

Se o professor não tem ciência do que seja tecnologia e de que tecnologias estão disponíveis para a educação; se ele não utiliza suportes tecnológicos além dos tradicionais disponibilizados nas salas de aula; se ele não é usuário das tecnologias digitais; como ele poderá saber quais são as aplicabilidades dessas tecnologias como mediadoras no ensino, na aprendizagem, na reelaboração de conhecimentos existentes, e na construção de novos conhecimentos (CORTELAZZO, 2012, p. 99).

Nesse sentido, há a necessidade de formação dos docentes que atuam no AEE frente ao manejo adequado das tecnologias digitais, conforme Santarosa, Conforto e Compagnoni (2014). As tecnologias na sala de AEE e as tecnologias digitais, quando acessíveis, podem vir a impulsionar novas práticas de empoderamento para professores e estudantes, com e sem deficiência.

A capacitação de professores não pode limitar-se ao aprendizado competente das ferramentas das TIC. Ainda, precisam estar muito claras as metas a serem alcançadas com o uso desses recursos. Isto requer a necessidade de que esses professores compreendam efetivamente os princípios e propostas implicadas na educação inclusiva, construindo atitudes genuinamente acolhedoras das diferenças e favoráveis à inclusão (GIROTO; POKER; OMOTE, 2012, p. 22).

As tecnologias digitais utilizadas na educação especial na perspectiva da educação inclusiva podem ser utilizadas como ou por meio das TA no AEE, proporcionando aos alunos acessibilidade à informação e comunicação, e desenvolvendo a autonomia e participação no processo de inclusão escolar de maneira diversificada. Galvão Filho e Damasceno (2008) esclarecem que as Tecnologias de Informação e Comunicação (TIC) como TA, ocorrem quando se pretende alcançar um objetivo específico, como a utilização do caderno eletrônico para o indivíduo que não consegue escrever no caderno comum de papel, sendo o computador uma ajuda técnica. Já as TICs, por meio da TA, é quando se pretende atender a um objetivo final, como a utilização de software e teclados adaptados, para que o aluno tenha acesso ao computador.

Portanto, perceber as tecnologias digitais na escola no contexto do AEE requer consubstanciar suas práticas a partir de novos olhares para a própria sociedade contemporânea, que incitam o uso das tecnologias no cotidiano. Dessa maneira, as instituições educacionais, como partes constituintes do contexto social, estão imersas nessas novas relações que se estabelecem e balizam a necessidade de novas práticas educativas potencializadas pelos recursos digitais, o que pressupõe um pensamento crítico diante do importante papel do professor nesse processo com vistas a contribuir efetivamente com as aprendizagens dos alunos PAEE. 


\section{Percurso metodológico}

Este estudo foi desenvolvido a partir de uma pesquisa bibliográfica com abordagem qualitativa. De acordo com Gil, a pesquisa bibliográfica permite "[...] um amplo alcance de informações, além de permitir a utilização de dados dispersos em inúmeras publicações, auxiliando também na construção, ou na melhor definição do quadro conceitual que envolve o objeto de estudo proposto" (GIL, 1994 Apud LIMA; MIOTO, 2007, p. 40).

Nesse contexto, realizamos um levantamento bibliográfico de artigos que versavam sobre o AEE e a utilização das tecnologias digitais nas SRM. Como critérios estabelecidos para o levantamento das pesquisas, utilizamos os seguintes descritores: atendimento educacional especializado; sala de recursos multifuncionais; tecnologias, tecnologias digitais e tecnologias de informação e comunicação, produzidos entre os anos 2016 e 2020. Durante esse processo foram avaliadas e selecionadas pesquisas que apresentassem no título e no resumo relação com o objeto proposto.

Em seguida, foram realizadas leituras completas das produções científicas. Ao fim das buscas foram catalogados onze artigos científicos encontrados no Portal de Periódicos da Coordenação de Aperfeiçoamento de Pessoal de Nível Superior (CAPES), Google Acadêmico e Scielo. Para subsidiar a análise dos dados, elaboramos um quadro (Quadro 1) com os principais dados de cada pesquisa (Autores, título e resumo dos resultados).

Quadro 1: Apresentação dos onze artigos selecionados e analisados

\begin{tabular}{|c|c|c|c|}
\hline \multicolumn{2}{|c|}{ Autores } & \multirow{2}{*}{$\begin{array}{l}\text { Título } \\
\text { Práticas de Ensino e Uso das } \\
\text { Tecnologias no Atendimento } \\
\text { Educacional } \\
\text { Especializado: enfoque } \\
\text { nas salas de recursos } \\
\text { multifuncionais. }\end{array}$} & \multirow[b]{2}{*}{$\begin{array}{l}\text { Resumo dos principais resultados } \\
\text { A pesquisa demonstra que os recursos tecnológicos } \\
\text { são coadjuvantes favoráveis no desenvolvimento } \\
\text { de novas habilidades e competências. Entretanto, } \\
\text { existem ainda dificuldades encontradas na utilização } \\
\text { das tecnologias, como a falta de conhecimento tecno- } \\
\text { lógico pelos professores, equipamento e sua manu- } \\
\text { tenção, internet e apoio técnico. }\end{array}$} \\
\hline 1 & $\begin{array}{l}\text { Cabral e } \\
\text { Bottentuit } \\
\text { Junior, } 2016\end{array}$ & & \\
\hline 2 & $\begin{array}{l}\text { Viana, } \\
\text { Vasconcelos e } \\
\text { Silva, } 2018\end{array}$ & $\begin{array}{l}\text { Práticas Inclusivas digitais } \\
\text { no contexto do atendimento } \\
\text { educacional especializado - } \\
\text { interfaces possíveis. }\end{array}$ & $\begin{array}{l}\text { Mostram como a articulação de teorias, métodos, } \\
\text { assim como o uso das TDIC's caracterizam os } \\
\text { aspectos didáticos que envolvem o trabalho nas } \\
\text { (SRM) e toda a dinâmica escolar, o que contribui para } \\
\text { a qualidade do ensino e da aprendizagem dos alunos } \\
\text { com deficiência. }\end{array}$ \\
\hline 3 & Silva, 2017 & $\begin{array}{l}\text { Atendimento Educacional } \\
\text { Especializado e as tecnologias } \\
\text { contribuindo para a aprendi- } \\
\text { zagem dos surdos. }\end{array}$ & $\begin{array}{l}\text { A escola pesquisada apresenta uma proposta signi- } \\
\text { ficativa de inclusão utilizando a tecnologia assistiva } \\
\text { na SRM, através de mobiliários, materiais didáticos } \\
\text { e pedagógicos, recursos de acessibilidade e equipa- } \\
\text { mentos específicos para o atendimento aos alunos } \\
\text { surdos. }\end{array}$ \\
\hline 4 & Santos, 2018 & $\begin{array}{l}\text { Jogos on-line no Atendimento } \\
\text { Educacional Especializado: } \\
\text { ampliando as possibilidades de } \\
\text { ensino/aprendizagem. }\end{array}$ & $\begin{array}{l}\text { Os resultados evidenciam que os quatro games } \\
\text { analisados na pesquisa podem ser utilizados como } \\
\text { recursos pedagógicos, mesmo não sendo criados para } \\
\text { fins educativos. }\end{array}$ \\
\hline 5 & Teixeira, 2019 & $\begin{array}{l}\text { O uso das TIC no processo de } \\
\text { aprendizagem dos estudantes } \\
\text { com deficiência. }\end{array}$ & $\begin{array}{l}\text { As TIC's vêm contribuindo significativamente } \\
\text { para a comunicação e a interação dos alunos, além } \\
\text { de potencializar a acessibilidade à informação e o } \\
\text { desenvolvimento cognitivo. A pesquisa aponta a } \\
\text { necessidade de formação de professor e SRM com } \\
\text { estruturas adequadas. }\end{array}$ \\
\hline
\end{tabular}




\begin{tabular}{|c|c|c|c|}
\hline \multicolumn{2}{|c|}{ Autores } & \multirow{2}{*}{$\begin{array}{l}\text { Título } \\
\text { Jogos digitais e aprimora- } \\
\text { mento do controle inibitório: } \\
\text { um estudo com crianças do } \\
\text { Atendimento Educacional } \\
\text { Especializado. }\end{array}$} & \multirow{2}{*}{$\begin{array}{l}\text { Resumo dos principais resultados } \\
\text { Os jogos digitais podem ser recursos alternativos às } \\
\text { intervenções que ocorrem no AEE para aprimorar } \\
\text { as funções executivas e melhorar as condições para } \\
\text { aprendizagem no contexto escolar. }\end{array}$} \\
\hline 6 & $\begin{array}{l}\text { Ramos e } \\
\text { Garcia, } 2019\end{array}$ & & \\
\hline 7 & $\begin{array}{l}\text { Becker, } \\
\text { Medeiros } \\
\text { e Lamazon, } \\
2019\end{array}$ & $\begin{array}{l}\text { O uso das tecnologias digitais } \\
\text { acessíveis como estratégia de } \\
\text { aprendizagem no Atendimento } \\
\text { Educacional Especializado } \\
\text { - AEE. }\end{array}$ & $\begin{array}{l}\text { O uso das tecnologias digitais acessíveis promovem } \\
\text { o desenvolvimento das habilidades funcionais dos } \\
\text { alunos com deficiência, que consequentemente } \\
\text { tornam-se mais independentes, contribuindo com } \\
\text { sua qualidade de vida, desenvolvimento da aprendi- } \\
\text { zagem, interação em sala de aula e inclusão escolar. }\end{array}$ \\
\hline 8 & $\begin{array}{l}\text { Spurio e Bian- } \\
\text { chini, } 2020\end{array}$ & $\begin{array}{l}\text { Caracterização física de salas } \\
\text { de recursos multifuncionais e } \\
\text { percepções de professores em } \\
\text { relação à presença de jogos e } \\
\text { tecnologia no atendimento } \\
\text { educacional especializado. }\end{array}$ & $\begin{array}{l}\text { Resultados revelam que os docentes têm percepções } \\
\text { favoráveis à integração das tecnologias digitais no } \\
\text { AEE, principalmente em relação aos jogos digitais. } \\
\text { Os participantes alegam melhoria no desenvolvi- } \\
\text { mento, na aprendizagem, no resgate da autoestima e } \\
\text { envolvimento no processo de aprendizagem. Entre- } \\
\text { tanto, a pesquisa destaca dificuldade no manuseio } \\
\text { dos recursos digitais pelos professores. }\end{array}$ \\
\hline 9 & $\begin{array}{l}\text { Queiroz e } \\
\text { Canuto, } 2020\end{array}$ & $\begin{array}{l}\text { Informática acessível no aten- } \\
\text { dimento educacional especiali- } \\
\text { zado: uma experiência local. }\end{array}$ & $\begin{array}{l}\text { Nos resultados obtidos, elencam-se propostas das } \\
\text { atividades pedagógicas e educativas desenvolvidas e } \\
\text { metodologias utilizadas para que os alunos possam } \\
\text { manusear o computador, verificando os efeitos, } \\
\text { avanços e resistências dos alunos com necessidades } \\
\text { educacionais especiais. }\end{array}$ \\
\hline 10 & $\begin{array}{l}\text { Dantas e } \\
\text { Coutinho, } \\
2020\end{array}$ & $\begin{array}{l}\text { As Tecnologias para a Educação } \\
\text { Inclusiva de pessoas com } \\
\text { deficiência: Uma Revisão } \\
\text { Integrativa. }\end{array}$ & $\begin{array}{l}\text { Os resultados obtidos apontam que a literatura relacio- } \\
\text { nada à temática proposta considera que essas tecnolo- } \\
\text { gias digitais e assistivas desempenham um papel crucial } \\
\text { na educação inclusiva. Por meio dessas tecnologias, os } \\
\text { educandos com deficiência apresentam uma aprendi- } \\
\text { zagem mais significativa, bem como independência, } \\
\text { autonomia e desenvolvem suas habilidades. }\end{array}$ \\
\hline 11 & $\begin{array}{l}\text { Matos, Santos, } \\
\text { Souza e Sadim, } \\
2020\end{array}$ & $\begin{array}{l}\text { Os recursos de acessibilidade e } \\
\text { Tecnologia Assistiva na Sala de } \\
\text { Recursos Multifuncionais nas } \\
\text { escolas municipais de Manaus/ } \\
\text { AM. }\end{array}$ & $\begin{array}{l}\text { Os resultados apontam que as salas foram providas } \\
\text { por um kit de recursos de Tecnologia Assistiva na } \\
\text { tentativa de as escolas terem acesso a esses recursos } \\
\text { e, consequentemente, o seu uso para com os alunos- } \\
\text {-alvo da educação especial, proporcionando um } \\
\text { ambiente mais acessível e aprendizagem eficaz. }\end{array}$ \\
\hline
\end{tabular}

Fonte: Elaborado pelos autores.

Para a organização e análise dos dados, utilizamos o método de análise do conteúdo que, segundo Franco (2008, p. 19), "O ponto de partida da Análise de Conteúdo é a mensagem, seja ela verbal (oral ou escrita), gestual, silenciosa, figurativa, documental ou diretamente provocada. Necessariamente, ela expressa um significado e um sentido".

Dessa maneira, os dados foram analisados com base na técnica de análise de conteúdo de Bardin (2011), que propõe que a análise de conteúdo se desenvolva seguindo três etapas básicas: a pré-análise, que consiste na organização dos dados coletados por meio dos instrumentos de pesquisa; a exploração da matéria, através da codificação dos dados, bem como a definição de um sistema de categorias; e o tratamento dos resultados por meio de processos de interferência e interpretação.

Seguindo essa compreensão, a análise dos resultados das pesquisas permitiu a organização de quatro categorias: 1) tecnologias digitais: percepções e conceitos no contexto do AEE; 2) contribuições do uso das tecnologias digitais no AEE; 3) dificuldades encontradas no uso das tecnologias digitais no AEE; e 4) superando as dificuldades para o uso das tecnologias digitais no AEE. 


\section{O que dizem as pesquisas acerca do uso das tecnologias digitais no AEE}

A partir das leituras dos artigos selecionados, discutiremos alguns pontos fundamentais que se mostraram recorrentes diante das ideias apontadas pelos estudos no que diz respeito ao uso das tecnologias digitais no AEE.

Seguem, nesta seção, algumas considerações sobre as percepções dos autores diante das tecnologias digitais, suas contribuições, dificuldades e sugestões diante do trabalho com o PAEE, que possam trazer à tona novas propostas de reflexão que favoreçam a sua aplicação no AEE.

Analisaremos as pesquisas selecionadas enfatizando a visão dos autores sobre a temática proposta e a contribuição das pesquisas para o enriquecimento do debate em relação ao uso das tecnologias digitais nas salas especiais.

\section{Tecnologias digitais: percepções e conceitos no contexto do AEE}

Diante dos artigos pesquisados, a percepção das tecnologias digitais perpassa suas possibilidades de atuação prática diante da necessidade e acessibilidade do PAEE, compreendendo-as como instrumento capaz de romper as barreiras, como apontam Becker, Medeiros e Lamazon (2019), utilizando a terminologia "tecnologias acessíveis", e Queiroz e Canuto (2020), na perspectiva de "informática acessível".

Também foram expostas as percepções das tecnologias como "recursos digitais de inclusão", apontadas por Silva (2017) e Dantas e Coutinho (2020), revelando as exclusões pelas quais comumente passam os alunos PAEE nas instituições escolares, assim como fora delas, tornando-se um fator preponderante para a necessidade do uso das tecnologias digitais no AEE.

Já Spurio e Bianchini (2020) e Matos, Santos, Souza e Sadin (2020) utilizam a denominação "tecnologia assistiva", inscrita no uso de programas e aplicativos que direcionam o estudante a novas possibilidades de aprendizagem. Cabe ressaltar que, entre esses recursos, Spurio e Bianchini (2020) entendem que o uso das tecnologias no AEE é perceptível a partir dos jogos digitais. Essa assertiva também é encontrada em Santos (2018) e Ramos e Garcia (2019), cujas pesquisas se inscrevem no campo das possibilidades de aprendizagens, avaliação e adaptação curricular a partir da imersão do PAEE nesses jogos.

Aponta-se, como referência das tecnologias digitais, o uso de "recursos tecnológicos" (notebooks, celulares e computadores), como indicam Cabral e Bottentui Junior (2016), Teixeira (2019) e Silva (2017). Cabe ainda salientar que, complementar a essa abordagem, a inserção dos computadores e, mais recentemente, dos notebooks nas escolas, foi fator marcante na constituição desse novo olhar para e com as tecnologias digitais no contexto da educação especial.

Observa-se, portanto, que o surgimento desse olhar para as tecnologias digitais pelos autores no contexto do AEE, pousa em uma postura que examina suas potencialidades práticas diante dos desafios encontrados pelos alunos PAEE, que podem encontrar no uso de recursos e equipamentos digitais novas perspectivas de aprendizagens e de eliminação de barreiras com vistas à inclusão.

\section{Contribuições das tecnologias digitais no AEE}

É unânime, entre os resultados evidenciados nas pesquisas, o reconhecimento do potencial das tecnologias digitais integradas à educação, principalmente no tocante ao processo de inclusão escolar de alunos PAEE, por proporcionar acessibilidade à aprendizagem, autonomia e desenvolvimento de habilidades, favorecendo, assim, a plena participação escolar e social desses alunos. Teixeira (2019, p. 153) enfatiza que a tecnologia se constitui num recurso "[...] que pode contribuir 
significativamente para a comunicação e interação dos estudantes com deficiência, ampliando para eles o grau das informações, a acessibilidade e o desenvolvimento cognitivo".

Corroborando com essa afirmativa, o estudo de Dantas e Coutinho (2020) avalia as tecnologias na educação inclusiva, sobretudo voltada às crianças PAEE, como agentes potencializadores na aprendizagem. Silva (2017) acrescenta que as metodologias diferenciadas, nas quais são usados recursos tecnológicos, contribuem com a inclusão e desenvolvimento significativo desses alunos.

É importante considerar que as tecnologias mais utilizadas no AEE demonstradas nas pesquisas são o computador com a utilização de Internet (ainda que o acesso seja restrito ou ausente em alguns contextos educacionais), programas de digitação de textos, redes sociais, Google e jogos. Dessa forma, reitera-se que, apesar da utilização dos recursos digitais no AEE, percebemos uma limitação quanto ao uso das tecnologias digitais, mesmo diante da gama de recursos acessíveis na internet. Essa afirmativa é observada no estudo de Cabral e Bottentuit Junior (2016, s.p), ao pontuarem que "[...] percebe-se que diante da diversidade de recursos hoje disponíveis na Internet, o uso dos mesmos no AEE ainda é bastante limitado". Para Masetto (2006, p. 160), "[...] a internet é um grande recurso de aprendizagem múltipla: aprende-se a ler, a buscar informações, a pesquisar, a comparar dados, a analisá-los, a criticá-los, a organizá-los. Desenvolvemos habilidades para utilizar e explorar este novo recurso tecnológico [...]".

\section{Dificuldades encontradas no uso das tecnologias digitais no AEE}

Apesar de as pesquisas serem favoráveis ao uso das tecnologias digitais nos ambientes do AEE, por proporcionarem o enriquecimento da inclusão escolar de alunos PAEE, algumas dificuldades são encontradas no decorrer desse processo.

Uma das principais dificuldades encontradas nas SRM, em que funcionam o AEE, é a precária qualidade na infraestrutura que, na maioria das vezes, é um espaço provisório e sem acessibilidade, que precisa adequação para receber os alunos, professores, recursos, materiais e equipamentos necessários para o atendimento. A pesquisa de Matos, Santos, Souza e Sadim (2020) enfatiza que nas salas de recursos multifuncionais os ambientes são limitados, com pouco espaço para mobilidade. Como revela a pesquisa de Spurio e Bianchini:

[...] algumas salas estão em situação precária com relação até aos jogos específicos para as deficiências. Nestes casos, por mais que o professor seja criativo em sua atuação, as atividades podem ficar restritas e até desinteressantes para o aluno (SPURIO; BIANCHINI, 2020, p. 212).

Já Cabral e Bottentuit Junior (2016) apresentam ainda como dificuldades em seus estudos a limitação no acesso à internet, número resumido de equipamentos, e ausência de apoio técnico e de manutenção na área da informática.

Outra dificuldade identificada no decorrer da análise das pesquisas corresponde à ausência de práticas pedagógicas diversificadas na utilização dos recursos digitais, o que nos leva a cogitar que um dos motivos disso ocorrer é pela falta de formação dos professores de AEE na área tecnológica. O estudo de Dantas e Coutinho (2020) revela a falta de qualificação docente para o manuseio dos recursos tecnológicos. Como enfatiza Schlünzen Junior:

O papel do professor e a sua redefinição devem ampliar suas competências para lidar com as transformações da Ciência e da Tecnologia. Esses são grandes desafios a serem superados, associados à capacidade de planejar e desenvolver no alunado as competências relacionadas a uma cultura audiovisual, digital e inclusiva que assegurem um nível de alfabetização digital e de cultura inclusiva. Além disso, saber integrar e usar pedagogicamente as TIC em sua prática 
profissional, de maneira a impregná-la em suas ações docentes, da mesma forma como as tecnologias estão impregnadas em nosso cotidiano (SCHLÜNZEN JUNIOR, 2012, p. 122).

Neste contexto, Santos (2018) salienta em seu estudo a atuação docente como um fator preponderante, visto que é o professor quem organizará as atividades e buscará recursos e metodologias para que o estudante da educação especial possa se desenvolver. Aqui, se faz necessário repensar as formas tradicionalistas e bancárias de transmissão de saberes para que novos métodos sejam incorporados pela escola, buscando diversificadas estratégias que rompam com esse tipo de ensino.

\section{Superando as dificuldades para o uso das tecnologias digitais no AEE}

Os artigos de Cabral e Bottentuit Junior (2016), Viana, Vasconcelos e Silva (2018), Teixeira (2019), Dantas e Coutinho (2020) e Spurio e Bianchini (2020) apresentam a formação continuada do professor na área das tecnologias digitais como umas das maiores necessidades evidenciadas no decorrer das práticas pedagógicas no AEE. Dessa maneira, percebemos que os docentes precisam de formação tanto no que corresponde ao processo de inclusão digital quanto para o uso pedagógico dos recursos digitais, uma vez que estes têm contribuído para a eliminação de barreiras educacionais e sociais. Segundo Silva et al. (2020, p. 66):

As ações de formação continuada de professores para imersão na cultura digital e, por conseguinte, nas práticas de letramentos digitais é uma necessidade que se apresenta na atualidade, todavia há que se pensar na necessidade dessas práticas vincularem-se às boas bases teóricas, que mobilizem os professores a refletir sobre os fundamentos epistemológicos e pedagógicos que darão sustentáculo às práticas de uso das TDIC nos processos ensino e aprendizagem dos estudantes.

Para além da necessidade do desenvolvimento da competência tecnológica pelo professor, são pontuadas também a necessária intencionalidade e mediação pedagógica frente ao uso das tecnologias digitais. Nesse sentido, Ramos e Garcia (2019) salientam a parceria com as famílias como um fator vital para o uso das tecnologias, sendo estas aliadas das aprendizagens dos alunos PAEE.

Essa parceria seria um fator basilar no trabalho com jogos digitais para além da escola. Nesse sentido, Santos (2018) aponta a necessidade de conhecer, de maneira mais pontual, as reais contribuições dos jogos digitais como recursos pedagógicos que facilitem a aquisição de habilidades e construção de conhecimentos, o que perpassa pela constituição de um novo olhar que extrapole os limites da concepção a que geralmente estão atrelados, ou seja, a do entretenimento.

Outros aspectos foram evidenciados no decorrer da análise dos artigos, que apontam a insuficiência na estrutura, organização e/ou apoio da SRM para a realização do acesso às tecnologias digitais. Nessa perspectiva, os estudos sugerem tanto a criação de políticas públicas que favoreçam o acesso às tecnologias digitais nos contextos escolares, como indicam Queiroz e Canuto (2020), como também incitam a urgência de maiores investigações sobre a temática, tendo em vista a necessidade de superação de barreiras, conforme demonstram Becker, Medeiros e Lamazon (2019).

Verifica-se, portanto, que as sugestões apontadas nas pesquisas concernentes ao uso das tecnologias digitais com alunos PAEE são diretamente constituídas como estratégias que intencionam o rompimento de barreiras nas instituições escolares, tendo em vista repensar possibilidades de inclusão na sociedade, cujas práticas educacionais foram forjadas num contexto historicamente excludente. 


\section{Considerações finais}

A partir do estudo realizado, foi possível notar que as tecnologias digitais muito podem somar na educação de alunos PAEE, sendo fundamental que as escolas contem com diversas estratégias de intervenções para realizar uma educação inclusiva, na qual os alunos tenham iguais oportunidades para aprender.

De acordo com as pesquisas analisadas, as tecnologias digitais por meio da TA constituem-se como um elemento significativo para auxiliar na aprendizagem e acessibilidade do PAEE. Através delas, o repertório de possibilidades educativas pode ser ampliado, tendo em vista a grande variedade de jogos, aplicativos e programas que podem funcionar como facilitadores dos processos de ensino-aprendizagem frente às especificidades de cada aluno.

Para tanto, as pesquisas apontam a necessidade da mediação pedagógica feita pelo professor do AEE, o qual precisará estar dotado de conhecimentos tecnológicos e pedagógicos, a fim de utilizar a tecnologia de maneira que sirva não somente como um suporte para antigas práticas, mas como uma aliada na construção de um conhecimento coparticipativo.

Apontamos ainda que as tecnologias digitais e assistivas, ao serem inseridas no AEE, contribuem para a acessibilidade e para o desenvolvimento intelectual dos estudantes na sala de recursos multifuncionais, sendo estendidos esses benefícios também à sala de aula de ensino regular.

É importante destacar também que, embora as pesquisas apontem dificuldades concernentes, entre outros fatores, à infraestrutura das SRM e à formação de professores capacitados para a utilização técnica e pedagógica dos recursos e equipamentos, ausência ou restrição de Internet e de projetos sociais e educacionais na esfera pública ou privada que atendem ao PAEE, novos olhares vêm sendo lançados às perspectivas de aprendizagem que podem ser desenvolvidas a partir do uso das tecnologias digitais com alunos PAEE.

Nessa perspectiva, cabe à escola e aos atores sociais nela envolvidos buscarem alternativas, de modo que venham a favorecer esses alunos, contribuindo, assim, para um ambiente mais inclusivo, em que todos tenham iguais oportunidades de aprendizagem.

É importante ressaltar ainda que, a partir da escolha criteriosa das pesquisas, observamos um número restrito de estudos acerca da temática, o que nos deixou surpresos, uma vez que as tecnologias digitais estão intrinsecamente relacionadas às mudanças sociais e educacionais na contemporaneidade. Nesse sentido, consideramos a necessidade de que se apresentem mais pesquisas voltadas para um debate frente ao uso das tecnologias digitais como recurso potencial para acessibilidade e aprendizagem dos alunos PAEE, assim como sejam formuladas políticas públicas que favoreçam a inclusão nesse contexto.

\section{Referências}

ALVES, Denise de Oliveira et al. (org.). Salas de recursos multifuncionais: espaço para o atendimento educacional especializado. Brasília, DF: Ministério da educação, Secretária de Educação Especial, 2006.

BAPTISTA, Claudio Roberto. Ação Pedagógica e Educação Especial: para além do AEE. In: JESUS, Denise Meyreles de; BAPTISTA, Claudio Roberto; CAIADO, Katia Regina Moreno. Prática pedagógica na educação: multiplicidade do atendimento educacional especializado, 2020. p. 43-61.

BARDIN, Laurence. Análise de conteúdo. Tradução de Luís Antero Reto e Augusto Pinheiro. São Paulo: Edições 70, 2011.

BECKER, Mirian Mirna; MEDEIROS, José Sodré; LAMAZON, Vanessa Lima. O uso das tecnologias digitais acessíveis como estratégia de aprendizagem no atendimento educacional especializado - AEE. Revista Gepesvida. Edição especial, v. 5, n. 13, 2019. 
BERSCH, Rita. Tecnologia Assistiva - TA. In: SHIRMER, Carolina R. et al. (org.). Deficiência Física. Brasília, DF: Ministério da educação, Secretária de Educação Especial, 2007. p. 31-36. Disponível em: http://portal.mec.gov.br/seesp/ arquivos/pdf/aee_df.pdf. Acesso em: 10 fev. 2021.

BRASIL. Constituição da República Federativa do Brasil. Brasília, DF, 1988. Disponível em: http://www.planalto.gov. br/ccivil_03/Constituicao/Constituicao.htm. Acesso em: 05 fev. 2021.

BRASIL. Decreto $n^{\circ} 7.611$, de 17 de novembro de 2011. Dispõe sobre a educação especial, o atendimento educacional especializado e dá outras providências. Brasília, DF: Ministério da Educação, 17 de novembro de 2011. Disponível em: http://www.planalto.gov.br/ccivil_03/_Ato2011-2014/2011/Decreto/D7611.htm. Acesso em: 15 jan. 2021.

BRASIL. Nota Técnica No 11, de 7 de maio de 2010. Ministério da Educação. Secretaria de Educação Especial, Brasília, DF, 7 de maio 2010. Disponível em: http://portal.mec.gov.br/index.php?option=com_content\&view=article\&id=17430\&Itemid=817. Acesso em: 10 fev. 2021.

BRASIL. Política Nacional de Educação Especial na Perspectiva da Educação Inclusiva. Ministério da Educação, Secretaria de Educação Especial, Brasília, DF, 2008. Disponível em: http://portal.mec.gov.br/seesp/arquivos/pdf/politica. pdf. Acesso em: 05 jan. 2021.

BRASIL. Resolução no 4, de 2 de outubro de 2009. Institui as Diretrizes Operacionais para o Atendimento Educacional Especializado na Educação Básica, na modalidade Educação Especial. Ministério da Educação. Conselho Nacional de Educação, Câmara de Educação Básica, Brasília, DF, 2009. Disponível em: http://portal.mec.gov.br/index.php?option=com_content\&view=article\&id=16761\&Itemid=1123. Acesso: 10 fev. 2021.

CABRAL, Mozanilde Santos Nunes; BOTTENTUIT JUNIOR, João Batista. Práticas de Ensino e Uso das Tecnologias no Atendimento Educacional Especializado: enfoque nas salas de recursos multifuncionais. Renote - Novas Tecnologias na Educação, Porto Alegre, v. 14, n. 1, p. 1-10, jul. 2016. Disponível em: https://www.seer.ufrgs.br/renote/article/ view/67356. Acesso em: 10 jan. 2021.

CORTELAZZO, Iolanda Bueno de Camargo. Formação de professores para uma educação inclusiva mediada pelas tecnologias. In: GIROTO, Claudia Regina Mosca; POKER, Rosimar Bortolini; OMOTE, Sadao (org.). As tecnologias nas práticas pedagógicas inclusivas. Marília: Oficina Universitária; São Paulo: Cultura Acadêmica, 2012. p. 93-120.

COUTINHO, Clara Pereira. TPACK: em busca de um referencial teórico para a formação de professores em tecnologia educativa. Revista Científica de Educação à Distância, v. 2, n. 4, jul. 2011. Disponível em: https://periodicos.unimesvirtual.com.br/index.php/paideia/article/view/197. Acesso: 10 jan. 2021.

DANTAS, Edja Soares; COUTINHO, Diógenes José Gusmão. As Tecnologias para a Educação Inclusiva de pessoas com deficiência: Uma Revisão Integrativa. Revista Ibero-Americana de Humanidades, Ciências e Educação. São Paulo, v. 6 , n. 12, dez. 2020.

FRANCO, Maria Laura Publisi Barbosa. Análise de conteúdo. 3. ed. Brasília, DF: Liber Livro, 2008.

GAlVÃO FILHO, Teófilo Alves; DAMASCENO, Luciana Lopes. Programa Info Esp: Premio Reina Sofia 2007 de Rehabilitación y de Integración. In: Boletín del Real Patronato Sobre Discapacidad. Ministerio de Educación, Política Social y Deporte, Madri, Espanha, n. 63, p. 14-23, abril 2008. Disponível em: http://www.galvaofilho.net/Programa_ InfoEsp_2009.pdf. Acesso em: 05 fev. 2021.

GIROTO, Claudia Regina Mosca; POKER, Rosimar Bortolini; OMOTE, Sadao. (org.). As tecnologias nas práticas pedagógicas inclusivas. Marília: Oficina Universitária; São Paulo: Cultura Acadêmica, 2012.

JANNUZZI, Gilberta Sampaio de Martinho. Diversidade Humana: disseminação e apropriação do saber. Anais do III Congresso Ibero-americano de Educação Especial. Foz do Iguaçu, vol. 1, 1998.

LEMOS, André. Alguns pontos para compreender a nossa época. In: LEMOS, André; CUNHA, Paulo (org.). Olhares sobre a Cibercultura. Porto Alegre: Sulina, 2003.

LIMA, Telma Cristiane Sasso de; MIOTO, Regina Célia Tamaso. Procedimentos metodológicos na construção do conhecimento científico: a pesquisa bibliográfica. Rev. Katál. Florianópolis, v. 10, n. esp., p. 37-45, 2007. Disponível em: https://www.scielo.br/pdf/rk/v10nspe/a0410spe.pdf. Acesso em: 17 dez. 2020.

MASETTO, Marcos T. de et al. Mediação pedagógica e o uso da tecnologia. In: MORAN, José Manuel; MASETTO, Marcos T.; BEHRENS, Marilda. Novas tecnologias e mediação pedagógica. 21. ed. rev. e atual. Campinas: Papirus, 2006.

MATOS, Maria Almerinda de Souza; SANTOS, Christiane Bruce dos; SOUZA, Danilo Batista de; SADIM, Geyse Pattrizzia Teixeira. Os recursos de acessibilidade e Tecnologia Assistiva na Sala de Recursos Multifuncionais nas escolas municipais de Manaus/AM. Revista Ibero-Americana de Estudos em Educação, Araraquara, v. 15, n. esp. 1, p. 932-947, maio 2020. 
QUEIROZ, Artur de Medeiros; CANUTO, Solange Alves Canuto. Informática acessível no atendimento educacional especializado: uma experiência local. Braz. J. of Develop. Curitiba, v. 6, n. 9, p.73775-73785, sep. 2020.

RAMOS, Daniela Karine; GARCIA, Fernanda Albertina. Jogos digitais e aprimoramento do controle inibitório: um estudo com crianças do Atendimento educacional especializado. Rev. Bras. Ed. Esp., Bauru, v. 25, n. 1, p. 37-54, jan./ mar. 2019.

SANTAROSA, Lucila Maria Costi; CONFORTO, Débora; COMPAGNONI, Maristela Vieira (orgs.). Tecnologia e acessibilidade: passos em direção à inclusão escolar e sociodigital. Porto Alegre: Evangraf, 2014.

SANTOS, Laércio Ferreria dos. Jogos on-line no Atendimento Educacional Especializado: ampliando as possibilidades de ensino/aprendizagem. Cadernos RCC\#12, v. 5, n. 1, mar. 2018.

SCHLÜNZEN JUNIOR, Klaus. Construção de ambientes digitais de aprendizagem: contribuições para a formação do professor. In: GIROTO, Claudia Regina Mosca; POKER, Rosimar Bortolini; OMOTE, Sadao. As tecnologias nas práticas pedagógicas inclusivas. Marília: Cultura Acadêmica, 2012.

SILVA, Albina Pereira de Pinho et al. Laboratórios de informática e a discursividade no processo de ensino e aprendizagem nas escolas estaduais da região Noroeste de Mato Grosso. In: STRAUB, Sandra Luzia Wrobel et al. (org.). Laboratórios de Informática das Escolas Públicas Estaduais Mato-grossenses: uma realidade discursiva da realidade educacional. - Cáceres: UNEMAT Editora, 2020. p. 48-73.

SILVA, Rose Madalena Pereira da. Atendimento Educacional Especializado e as tecnologias contribuindo para a aprendizagem dos surdos. Diversitas Journal, v. 2, n. 2, maio/ago. 2017.

SOMOS EDUCAÇÃO. Raio-x da educação inclusiva no Brasil: um panorama da educação especial sob a perspectiva da inclusão no país, 2020. Disponível em: https://conteudos.somoseducacao.com.br/lp-e-book-raio-x-da-educacao-inclusiva-no brasil?utm_source=fb-somos-ads\&utm_medium=CPC\&utm_campaign=lp-e-book-raio-x-da-educacao-inclusiva-no-brasil. Acesso em: 05 jan. 2021.

SPURIO, Mara Silvia; BIANCHINI, Luciane Guimarães Batistella. Caracterização física de salas de recursos multifuncionais e percepções de professores em relação à presença de jogo. Educação, Artes e Inclusão, Santa Catarina, v. 16, n. 3, jul./set. 2020. Disponível em: https://www.revistas.udesc.br/index.php/arteinclusao/article/view/15110. Acesso em: 10 jan. 2021.

STRAUB, Sandra Luzia Wrobel et al. Os laboratórios de informática: infraestrutura, formação continuada e o processo de ensino e aprendizagem no contexto da rede estadual de ensino na região norte e microrregião norte do Araguaia do estado de Mato Grosso. In: STRAUB, Sandra Luzia Wrobel et al. (org.). Laboratórios de Informática das Escolas Públicas Estaduais Mato-grossenses: uma realidade discursiva da realidade educacional. Cáceres: UNEMAT Editora, 2020. p. 74-124.

TEIXEIRA, Maria de Lourdes. O uso das TIC no processo de aprendizagem dos estudantes com deficiência. SCIAS Educação, Comunicação e Tecnologia, Minas Gerais, v. 1, n. 1, p. 127-157, 2019. Disponível em: https://revista.uemg. br/index.php/sciasedcomtec/article/view/3991. Acesso em: 10 jan. 2021.

TERUYA, Tereza K. Trabalho e educação na era midiática: um estudo sobre o mundo trabalho na era mídia e seus reflexos na educação. Maringá: Eduem, 2006.

VIANA, Flávia Roldan; VASCONCELOS, Jásia Sara de Lima; SILVA, Layse Kelly Santos da. Práticas Inclusivas digitais no contexto do atendimento educacional especializado: interfaces possíveis. Prometeu, ano 4, n. 4, p. 1-17, 2018.

Data de submissão: 15/05/2021

Data de aceite: 25/06/2021 